\title{
THE ISSUE OF DIGITIZING OF HISTORICAL HERITAGE ON THE EXAMPLE OF SELECTED HISTORICAL CLOCKS
}

\author{
Klára Rybenská \\ University of Hradec Králové (Hradec Králové, Czech Republic) \\ ORCID: http://org/0000-0001-9333-3063
}

\section{INTRODUCTION}

Nowadays, digitization is characterized by relatively easy access to digital content through media such as the Internet or television. Using the Internet mainly is now an integral part of most people's lives, and it is no different with other technologies. It has proven that one of the ways in which artefact institutions can keep in touch with visitors is, for example, through online web exhibitions, and this not only during the coronavirus pandemic. The modern concept of these exhibitions can be conceived not only as video (especially the highly valued $360^{\circ}$ ), but also as the presentation of three-dimensional digitized objects, which can also be viewed in this case from all digitized sides.

In general, many issues are addressed in the world of digitization of cultural heritage. These concern not only 2D but also 3D digitization of historical objects. Two-dimensional objects (such as documents, writings, books or other similar documents) and especially threedimensional objects are documented not only in traditional ways, but also through advanced methods of digitization through modern technology. It is no exception that digital museums are set up, which not only promote opportunities for public understanding of cultural heritage, but are also highly respected, especially by the younger generation who spend a lot of time in the digital environment [1].

The very digitization of historical artefacts, both $2 \mathrm{D}$ and especially $3 \mathrm{D}$, can hide many problems. It all starts with selecting a suitable object for digitization. The process continues through the choice of a good digitization method and scanner (or similar tool) through the scanning itself, then the editing and finishing of 3D scans to the creation of 3D models. This may be followed by the possible need to solve the subsequent presentation of objects (most often via the Internet). The whole process rarely proceeds without minor or even major glitches in the digitization making it necessary not only to edit but sometimes even to rescan.

The aim of the article therefore is to discuss not only the issue of $3 \mathrm{D}$ digitization of smaller objects, but also the possibilities that digitization brings. It can be used to promote and bring history to life again through modern technology but also to maintain the credible appearance of individual objects into the future.

The objects that have been digitized and exemplified in this study are historical clocks from different periods. These clocks come from the museum in Náchod in the Czech Republic and their digitization has been taking place since 2020 thanks to a project called Auxiliary Sciences of History between Traditional and Modern Approaches in 2019/2020, which was implemented under the auspices of the Philosophical Faculty of the University of Hradec Králové.

However, one must bear in mind that the aim of this article is not to describe the clock itself as historical objects, but as objects of digitization. The article therefore focuses mainly on the technological side of things. Last but not least, it also touches on the problems that the digitizer can most often encounter when scanning 3D objects and not only by the conservational institution.

\section{PROBLEMS WITH 3D DIGITIZATION OF SMALLER OBJECTS}

If we look back at history we see that computer technologies have been developed for quite some time. The first digital computers were made in the 1930s. However, their real inventor is considered to be Charles Babbage, who already in the 19th century invented the basic 
principles of machine operation which could solve complex calculations [1]. This was, if you like, the forerunner of the computer. The development of technology then rapidly accelerated and with it the exponential growth of computer performance. This inevitably led to the overall improvement and invention of new modern technologies gradually enabling these devices to reach various areas of human life [2]. Historical sciences are no exception. Digitization is often an inflected term nowadays and in relation to cultural heritage, which is a legacy of monuments (buildings, books, works of art, artifacts ...) inherited from past generations.

Not all these material monuments have been preserved. We only have a written record of some of them (on the basis of which, under certain circumstances, such a monument can also be revived in a three-dimensional computer model) [1]. But those that still exist, whatever their condition, are subject to the gradual action of the ravages of time.

If we talk about digitization, let's just say that it is a process in which the object is scanned into digital form. The spatial digitization itself is then also extended by spatial information, i.e. information about the position of the scanned object, its dispositions, structure and dimensional proportions. In addition to the spatial position of the scanned point, its characteristics (a property of the material, which is characterized by the density of the surface in shades of gray and the like) are all vital information. Digitization itself should always be performed at the highest level of possible digitization to make it possible to obtain the best data. The chosen digitization method should ideally be contactless and verified [15].

Scanning is then the process by which a device called a scanner converts a visual page of an object into a binary virtual form. The result of 3D spatial scanning with current technology is usually a point cloud. For each point of a similar cloud, its position relative to the scanned position is known [15].

Digitization, in either 2D or 3D, has many advantages. It is not just a matter of protecting memorials and making such works accessible to the public, which would otherwise not be possible to see or view in more detail. There are also advantages in the field of pedagogy (possible use as teaching aids) and in the field of motivation for further study of history. Digitized cultural heritage can be an engaging tool to attract the general public to museums or to visit various (perhaps already extinct) monuments [14]. In order for similar monuments to be preserved for future generations, one of the possibilities is to convert a material object into a three-dimensional, computer or similar device that can be displayed.

The creation of $3 \mathrm{D}$ objects then occurs either by modeling (for example, on the basis of period sources) or digitization, for which 3D scanners, measuring machines or various methods of photogrammetry or RTI are most often used.

A 3D scanner is a device that allows us to analyze an object or the environment of the real world by collecting data on its shape and possibly appearance [3] (for example, color, in this case we say that the scanner is able to capture the so-called texture). This accumulated data can then be used to build digital 3D models. Many technologies, or rather tools, can be used to create 3D objects. However, each of these technologies has its own limitations (for example, optical technologies may encounter problems in digitizing glossy, mirror-like or transparent objects), advantages and disadvantages, and last but not least, such technology can also be relatively expensive. To obtain 3D digitalizats, it is also possible to use scanners with structured alternating light, which are contactless, or even computed tomography and various other options. The accumulated data can be used in a wide range of programs and applications. They are most commonly used in the entertainment industry for the production of films and video games, including virtual, mixed or augmented reality. However, industrial design, medicine, reverse engineering, prototype designs, various quality controls and most noticeably in the process of 3D digitization also penetrates the digitization of cultural historical artifacts [3].

If we talk about the digitization of smaller objects, we must specify which objects are involved. We will not describe coins or seals in this article. We will focus on the historical clock. Many researchers may find that scanning clocks is a relatively easy matter. It may or may not be so. Digitization could be relatively easy if it was a completely problem-free object for 3D 
scanning or alternatively, if it were necessary to scan its lower part (and then connect it to one of the programs). Last but not least, we could use, for example, one of the sophisticated programs for digitization through smart devices (smartphones, tablets), such as Qlone or Trnio (available mainly for the iOS, iPadOS operating system, in the case of Qlone also for Android versions). However, it is probably not necessary to add that in this respect it is appropriate to have such a smart device, that has very high quality hardware (for example, iPad PRO 2020, iPhone 8 and higher, etc.). Even in this respect the resulting 3D object is not always perfect and we probably could not use it for archiving. Even so, it is necessary to mention this, because similar technologies exist and are constantly evolving. It is possible that in a few years it will be common for serious and professional digitization of selected objects to take place through smart devices and their applications.

However, we can classify the objects we have digitized as follows:

- Wall clocks,

- Table clocks,

- Clocks with a hanging mechanism (for example in the form of cones),

- Clocks with glass cover that protects the dial,

- Clocks with free (uncovered) dial,

- Wooden, ceramic, metal or clocks made of other materials,

- Clocks closed or with cross-sections (with the possibility of watching the clockwork),

- Glossy clocks,

- Matte clocks,

- Clocks with moving parts,

- Completely statistical clocks,

- A clock that can be built (usually a table clock),

- Recumbent clocks (usually a wall clock),

- Clock that are too bright,

- Clock that are too dark,

- ....(Here we just have to point out that this categorization was artificially created rather for an overview of what hours must be taken, into account when digitizing. What can we deal with as experts in the digitization of historical monuments?)

It is therefore certain that the issue of $3 \mathrm{D}$ digitization of not only historical clocks can be very troublesome. Therefore, in the article we will focus not only on the process of 3D digitization itself, but we will also point out the problems we encountered and how we (could or couldn't) solve them.

\subsection{Selected tools for 3D digitization}

There are many types of tools and technologies for 3D digitization as well as technologies and methods of 3D digitization itself. The techniques used for 3D digitization of cultural heritage are related to the specific needs of said object. The digitization technology itself depends on the quality of special hardware, software and also on the ability of the digitizer, who does not only have to digitize, but is often expected to be able to control a 3D modeling program. Even 3D digitization itself may have to be performed only through a 3D scanner, but also through the already mentioned smart technologies (having quality hardware, but also specific software) or using the method of photogrammetry $[1,11]$. However, for the purposes of possible archiving of digitized images, 3D digitization must be very accurate (or have an accuracy of better than $1 \mathrm{~mm}$ in each direction, in order to obtain as much detail as possible when digitizing the object).

Therefore, if we categorize the $3 \mathrm{D}$ digitization of cultural content we will primarily deal with the size of the objects to which the digitization applies. Due to technical limitations and application requirements, it is necessary to distinguish between the digitization of the objects themselves and then the entire monuments (which can be statues or even buildings) [11]. 
In our technology laboratory, we have several devices that are able to either measure objects or directly 3D digitize. We mostly use optical contactless scanners.

Here we just have to point out that this categorization was artificially created rather for an overview of what must be taken, into account when digitizing. So, what can we deal with as experts in the digitization of historical monuments?

Table 1. Description of 3D scanners and their characteristics which we used for the digitization of historical clocks. The description of these scanners is mainly based on the documentation of the manufacturers of individual devices. The reality may be a little different

\begin{tabular}{|c|c|c|}
\hline Device name & Digitizing technology & Basic description \\
\hline ATOS Compact scan $2 \mathrm{M}$ & $\begin{array}{l}\text { LED Blue Light (GOM). It is a } \\
\text { technology working on the } \\
\text { principle of narrowband } \\
\text { projection of blue light from } \\
\text { GOM. This technology allows } \\
\text { accurate measurement of the } \\
\text { object regardless of the lighting } \\
\text { conditions of the environment. [4] }\end{array}$ & $\begin{array}{l}\text { Measuring device with measuring } \\
\text { volume } 125 \times 90 \times 90 \text { mm to } \\
500 \times 380 \times 380 \mathrm{~mm} \text {. Digitization of } \\
\text { larger objects in parts is possible. } \\
\text { There is a problem with smaller } \\
\text { objects. Does not scan with } \\
\text { texture. }\end{array}$ \\
\hline $\begin{array}{l}\text { David SLS-2 Scanner 3D } \\
\text { (Currently, it can also be } \\
\text { found under the name HP } \\
\text { 3D SLS Pro S2. [6]) }\end{array}$ & $\begin{array}{l}\text { The principle of digitization } \\
\text { through structured light (The } \\
\text { method of projecting a known } \\
\text { pattern (usually a grid or } \\
\text { horizontal stripes) onto a scene or } \\
\text { object is called structured light. } \\
\text { The way in which the light } \\
\text { subsequently deforms on impact } \\
\text { with the surface allows the } \\
\text { camera system to calculate the } \\
\text { depth of the object and other } \\
\text { information about the surface of } \\
\text { the objects on which the cameras } \\
\text { are focused). [5] }\end{array}$ & $\begin{array}{l}\text { Scanner with the size of the } \\
\text { digitized object in the range of } 60 \text { - } \\
500 \mathrm{~mm} \text {. It is possible to scan } \\
\text { texture. }\end{array}$ \\
\hline
\end{tabular}

Table continuation 2

\begin{tabular}{|l|l|l|}
\hline Device name & \multicolumn{1}{|c|}{ Digitizing technology } & \multicolumn{1}{|c|}{ Basic description } \\
\hline Shining 3D EinScan-SE & $\begin{array}{l}\text { Digitization through the method } \\
\text { of structured light. }\end{array}$ & $\begin{array}{l}\text { The size of the digitized object is } \\
\text { in the range of 30 - 200 mm (using } \\
\text { an automatic turntable), then 30 - } \\
700 \mathrm{~mm} \text { (without a turntable). It is } \\
\text { possible to scan texture. }\end{array}$ \\
HP Sprout Pro G2 & $\begin{array}{l}\text { Digitization through a DLP } \\
\text { projector combined with a 3D } \\
\text { webcam that has Intel RealSense } \\
\text { technology (thanks to this } \\
\text { technology, it is possible to } \\
\text { capture not only 3D but also 2D } \\
\text { objects. This device also has a } \\
\text { certain touch pad, which can also } \\
\text { be used as a drawing tablet). [7] }\end{array}$ & $\begin{array}{l}\text { The digitized object is } \\
\text { between } 80 \text { - 200 mm. }\end{array}$ \\
Artec Leo & $\begin{array}{l}\text { The principle of digitization } \\
\text { through structured blue light. }\end{array}$ & $\begin{array}{l}\text { The size of the digitized object can } \\
\text { start at 5 mm, the largest possible }\end{array}$ \\
\hline
\end{tabular}




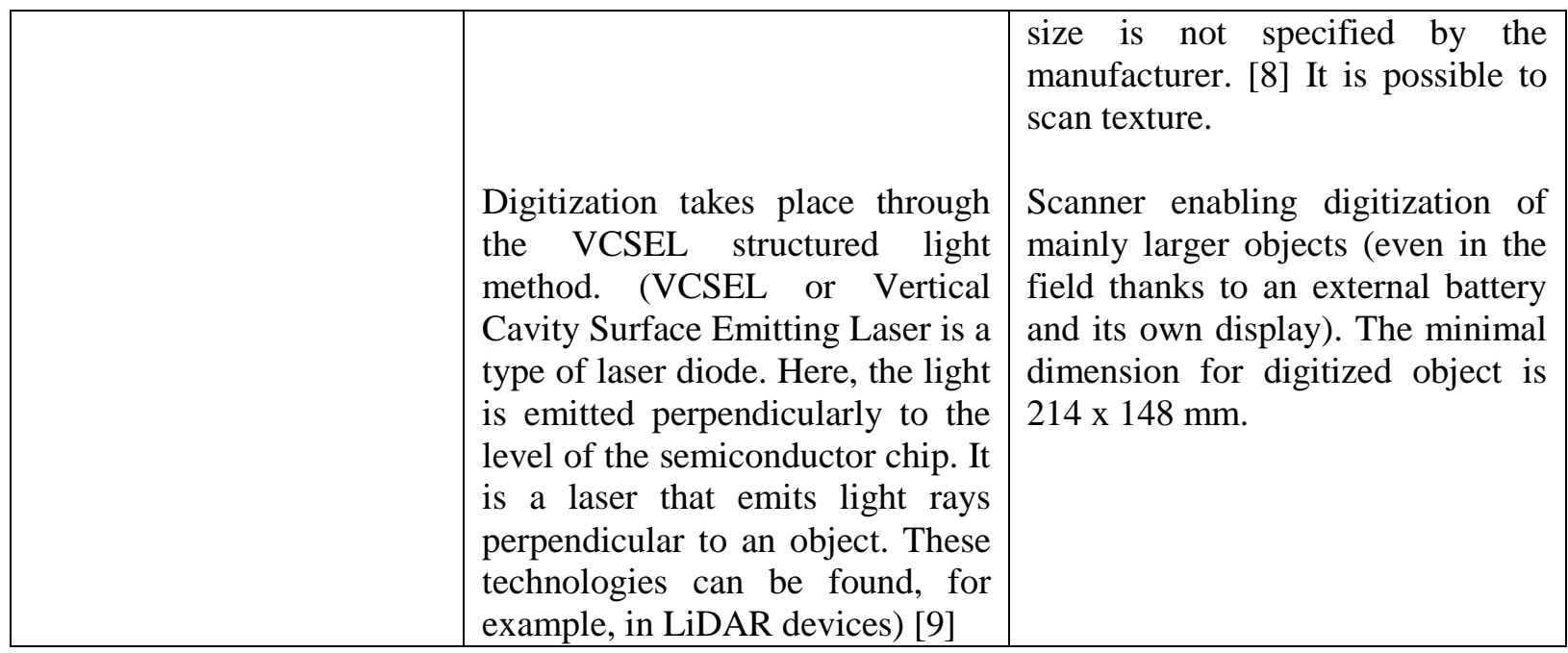

Now we see that each of our scanners has different options. Therefore, the approaches to digitization with these individual tools will be different. These scanners also have their own specific software with which the digitizer often has to learn to work. Not every one of these scanners allows you to digitize all objects (not least because of the sizes at which the scanners can work).

\section{PROCEDURE OF 3D DIGITIZATION OF SELECTED HISTORICAL CLOCKS}

The digitized objects, i.e. the historical clocks that we digitized, are of various sizes (from approx. $100 \mathrm{~mm}$ to approx. $400 \mathrm{~mm}$ in height and width). They are made of different materials. The classification of the clocks described above fully agrees in this regard. Therefore, the digitization of each of the objects is very specific.

The tools (3D scanners) we used, are described in Table 1 above. First, we divided the clocks into similar categories (size, material and their properties, problematic pieces...). The latter case, the so-called "problematic pieces", marked clocks that had shiny parts, transparent parts, too rugged a surface or were variously perforated, or if it was possible to see a watch movement through the individual parts or had a chain attached to them or alternatively, a clock with moving parts that could not be removed. More in picture number 1 .

Given the experience of the past in the field of 3D digitization it was certain that not every scanner would be suitable for capturing 3D digitals of clocks. The ATOS Compact Scan $2 \mathrm{M}$ was the first to be phased out. Although this device is a state-of-the-art technology and has highly accurate measurements (that is why GOM devices are often used, for example, in the field of reverse engineering), the scanner was not used for this digitization. This was because the technology was not able to capture the texture. 


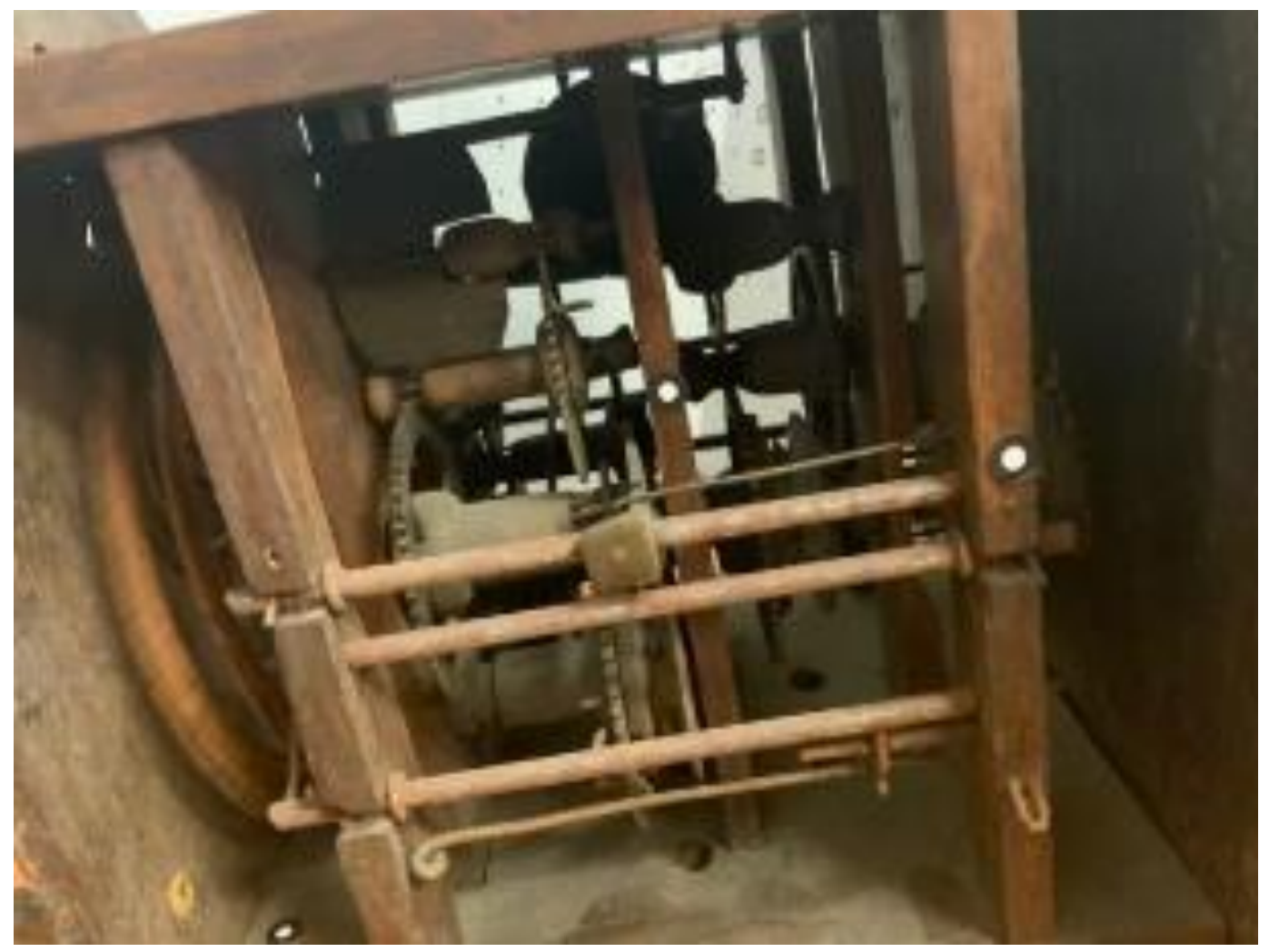

Figure 1: Example of a clock that has an exposed clock machine.

The visible black and white dots are reference points.

Some types of scanners use them to focus on a digitized object in space.

In this case it is used by the ATOS Compact Scan 2M measuring device

Due to the fact that it is assumed that the created 3D models will be exposed and also their possible archiving, digitization without texture is not a suitable solution. Of course, the texture can be photographed under certain circumstances and added to the models themselves later in one of the 3D modeling programs. However, the goal was to find a fast, functional and, if possible, the least demanding solution, even with the fact that the number of historic objects to be digitized is likely to increase in our workplace. Last but not least, because the journey from digitization to the final 3D model can sometimes be longer and more problematic there was no need to add additional tasks.

The second scanner we eliminated for digitizing these objects was the HP Sprout Pro G2. This multifunctional digitizing device is very useful outside of sports for relatively fast and convenient digitization of some objects, which, for example, would need to be quickly sent to someone for a demonstration. However, the resulting digitized results are usually not of such quality that they can be considered as models for exhibition or long-term archiving.

The scanner we also did not intend to use was the David SLS-2 Scanner 3D. This device is very capable in the core and at one time was one of the better technologies. Undoubtedly, it can digitize various objects and the quality of the resulting models is not bad. On the other hand, after the digitization process the gradual folding of the individual parts together and the creation of models are relatively time-consuming. Despite the fact that it is possible to use an automatic tool for assembling individual elements it unfortunately does not always work properly. For these reasons, we also rejected this device. We have 3 scanners left to evaluate. The Shining 3D Einscan - SE, the Artec Space Spider and Artec Leo.

After knowing which clocks to digitize, we selected one clock shortcut from each category and checked in turn whether our assumption of disabling the scanners was correct. Figure 2 shows digitization through the HP Sprout Pro G2 multimedia device. Despite the userfriendly digitization, the very friendly and intuitive environment and control, the resulting digitizers are unsuitable for our needs. 

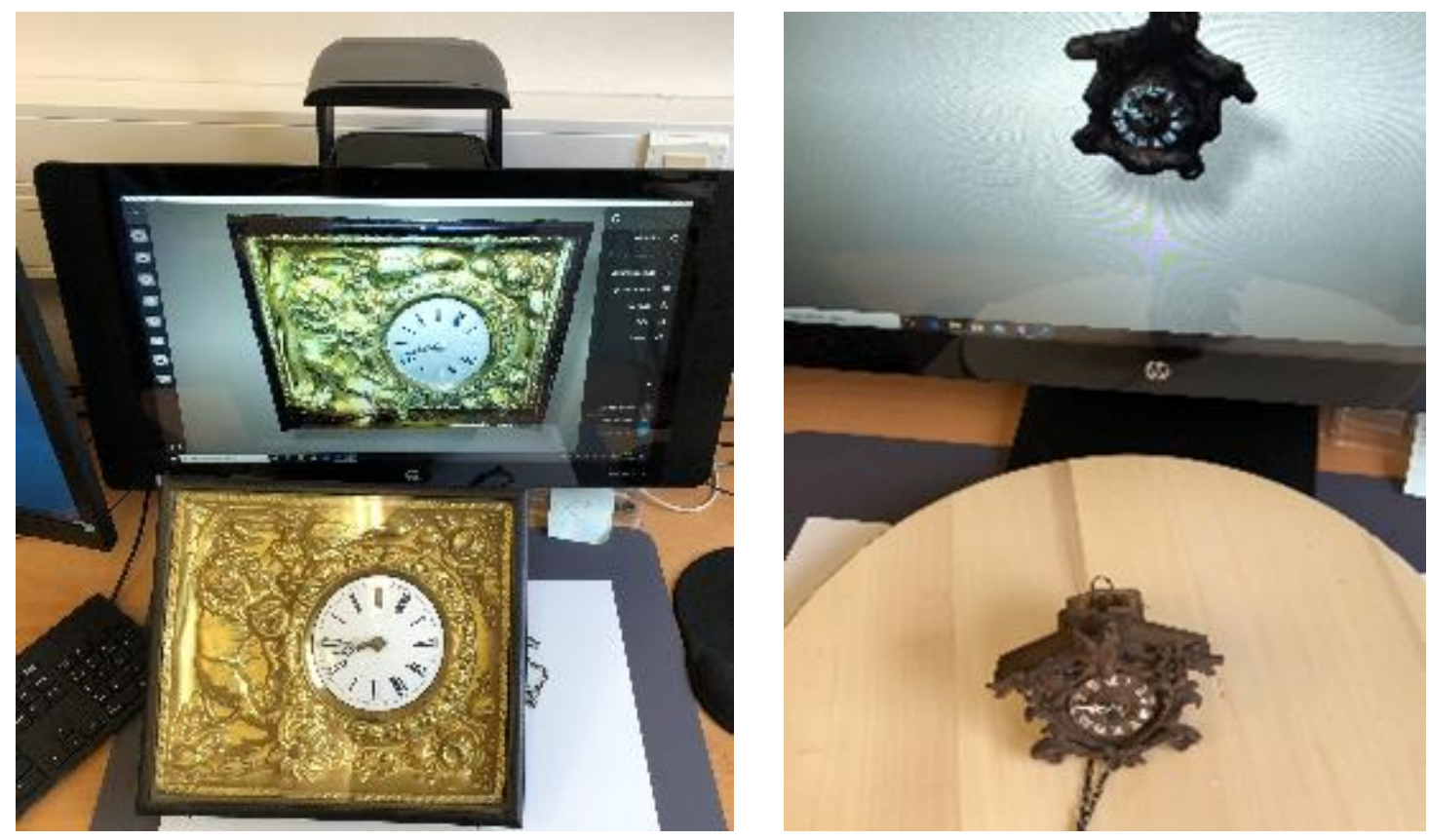

Figure 2: HP Sprout Pro G2 digitization process. During digitization it is necessary to rotate the object manually. The resulting model and its comparison can be seen in the picture.

Left - a problem with larger clocks that are shiny and have a glass lid.

Right - a smaller wall clock with a movable chain, a rugged surface and an internal view of the watch movement (not shown in the picture)

Similarly, we tested another device, the David SLS-2 Scanner 3D which could be used but working with it was relatively lengthy and ATOS Compact Scan 2M, a measuring device that does not capture texture (more in Figure 3). In addition, none of these devices have worked very well in digitizing shiny or too dark surfaces. However, this is a common problem with most $3 \mathrm{D}$ scanners [10]. Finally there remains the last 3 scanners which we will discuss in the text below.
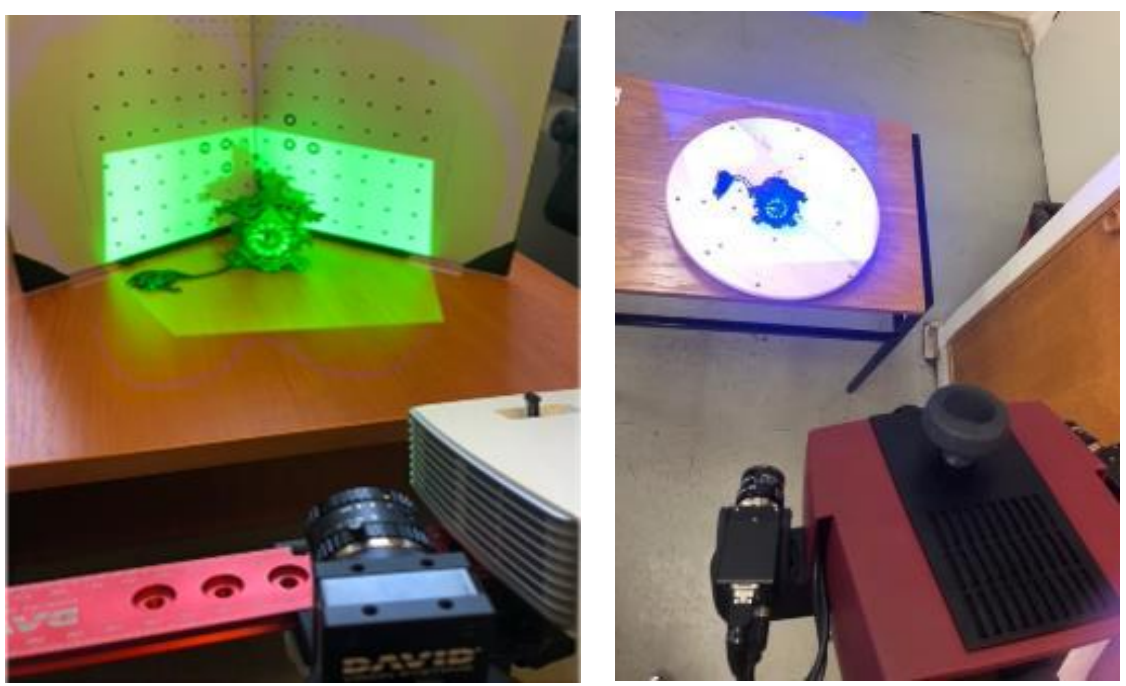

Figure 3: Digitization through the David SLS-2 Scanner 3D scanner (left) and the ATOS CompactScan 2M measuring device

The scanners we expected to use were Shining 3D Ein Scan-SE, Artec Space Spider and Artec Leo. We chose the first of them, i.e. Ein Scan, both for its relatively easy operation, but also for fast work with the software. And Artec scanners are among the best technologies for 3D scanning, so we assumed they would be the best for our needs. When digitizing with Ein Scan, we could not count on the possibility of scanning larger objects (certainly not automatically with 
a rotary table, and in most cases, it was possible to digitize only smaller objects with this scanner). Well we could only use this scanner to digitize two smaller clocks. It must be said that one of these objects (ceramic wall clocks) was quite difficult to digitize, because it was shiny and too bright. Despite this, the scanner coped very respectably with Artec Spider. However, for the remaining objects, this device was also weak.

For all these reasons, we were in the end, left with only the devices from Artec for digitization. Each of these devices that we have at our disposal is suitable for a different area of digitization. While Spider is better for scanning smaller and more articulated objects (that's why we considered it our favorite), Leo is mainly used for digitizing large monuments (including statues, rooms and the like).

The advantage of both scanners is in digitization and real-time digitization. Basically, we connect Spider to a computer, turn on Artec Studio, start scanning, and get started (without the need for calibration, as is often the case with previous scanners). On the screen we see how individual three-dimensional images are taken (Figure 4). After the digitization, we can try either automatic connection, or, if the individual scans require it, we can of course connect them ourselves (which is still a relatively fast and intuitive matter). We approach the actual connection mainly when we digitize the object from all sides (also from the one on which it is placed).

Alternatively, we can do this when the automatic connection fails. With the added software, we can do almost anything such as partially modelling or otherwise modifying the resulting model. Of course, the texture is captured during the scan. Here, too, it is possible to edit it later. The resulting 3D model can be exported to various formats (with or without texture, for archiving, presentation or for printing on a 3D printer, such as *.STL, *.OBJ, *.PLY and many others).

Usually, the glossy surface can be combated either by precise lighting or by dusting the object with a special spray, which evaporates within a few minutes. Alternatively, powder or crushed chalk can be used. However, we do this only on those buildings where it is possible (after consultation with the administrator of the relevant museum collection) to avoid damage to the building.

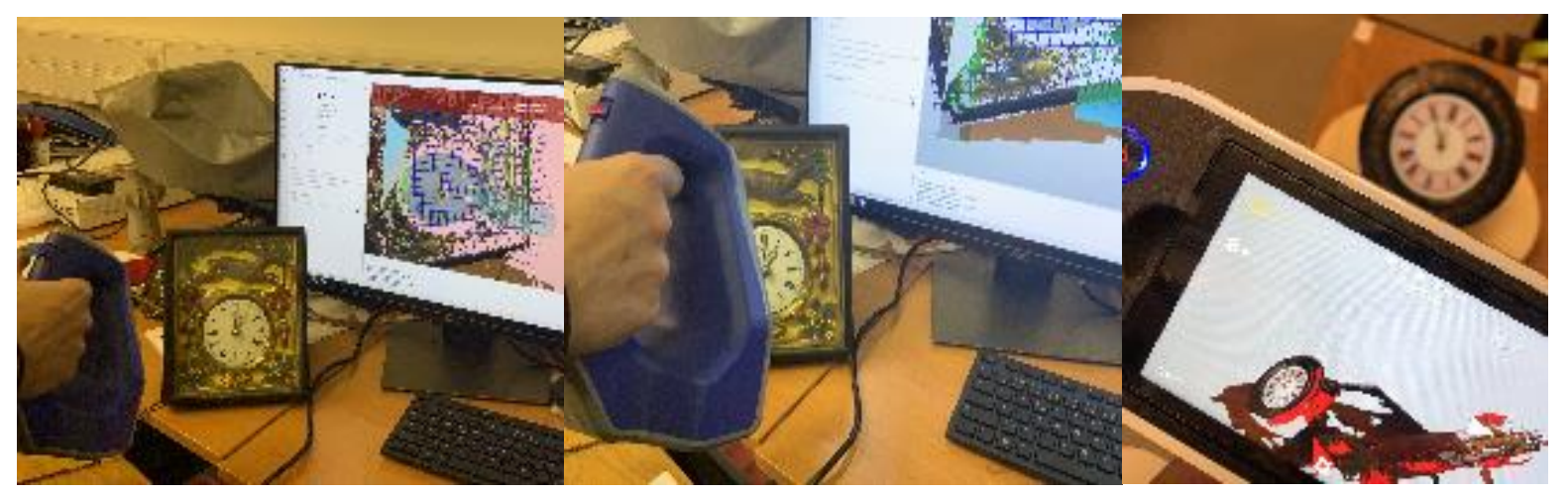

Figure 4: Left clock digitization process. In the background you can see a part of the model on the monitor which is also captured with the texture. If the software throws up an error then entire image must be recalculated. It is then possible to continue digitizing. The image on the right is the digitization process with the Artec Leo scanner. The scanner has a small display so it is necessary

to connect it to the computer only in the case of data transfer to the Artec Studio program, in which the resulting 3D model will be modified and created

However, even the Artec Spider did not cope with all the clocks. Especially with the larger ones, which had many parts, it had quite a problem. Well we used our last scanner, Artec Leo. Although we expected it to be more suitable for really large objects (e.g. over $500 \mathrm{~mm}$ ), we were pleasantly surprised. All the clocks that were more complicated for Artec Spider, Leo digitized very well and quickly (right part of Figure 4 above). In the first phase several dozen scans were created every hour which could be around hundreds of images from which we later composed the resulting 3D objects (see Figure 5). 

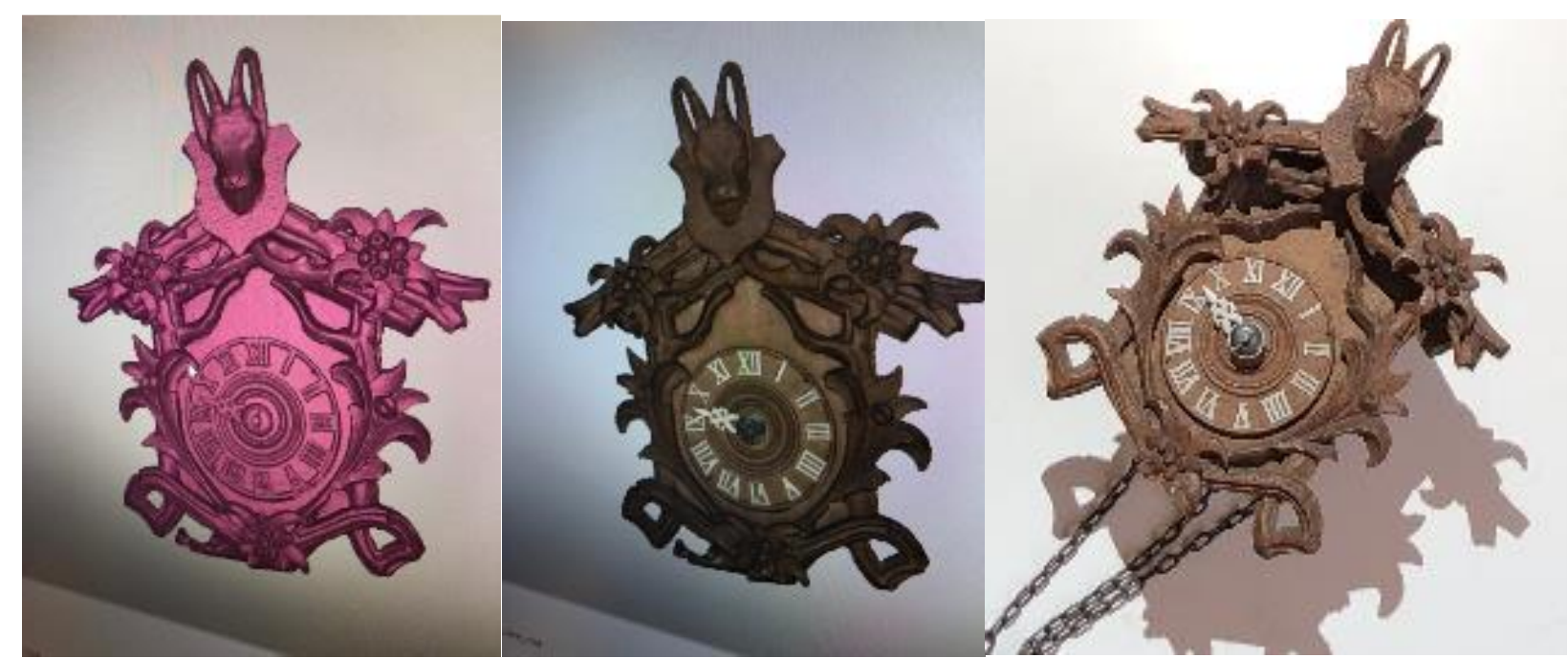

Figure 5: Left created 3D model without texture. In the middle is the already mapped texture of a 3D clock model. The scans and models were created using the Artec Space Spider scanner and Artec Studio. On the right, the original historical clock. It can be seen that the resulting texture of the model (middle) is darker than the illuminated model. The texture can be lightened. The model also lacks a chain and cones (which are not visible in the picture).

Both will be modeled separately in a 3D modeling program

This was basically just the beginning, as many models had to be rescanned because we did not obtain objects of sufficient quality during the first digitization. It was also necessary to model or otherwise modify some scanned parts that were difficult to detect (for example, shiny or too dark parts). Last but not least, the moving part (for example, a chain with a cone as a clock weight) had to be completely modeled. The chain, like other perforated objects, is very difficult to digitize. We checked this, many times even when trying to digitize the clock which either intentionally or due to damage was missing the side parts and thus could not be seen inside the watch movement. We were unable to scan such a part. In this respect, a solution is offered - to take quality pictures and replace the part with a photo as a texture or, alternatively, to use the photogrammetry method to take a 3D model through photographs that create a three-dimensional model. Finally, one could just model the entire machine. Of course, it would also be possible to disassemble the clock, scan it in parts and then fold it. However, this is almost unthinkable because a real specialist in lessons of this kind, would have to take part. We must also appreciate that due to the nature of the scanned object (an historical monument), it could be damaged. We couldn't allow that.
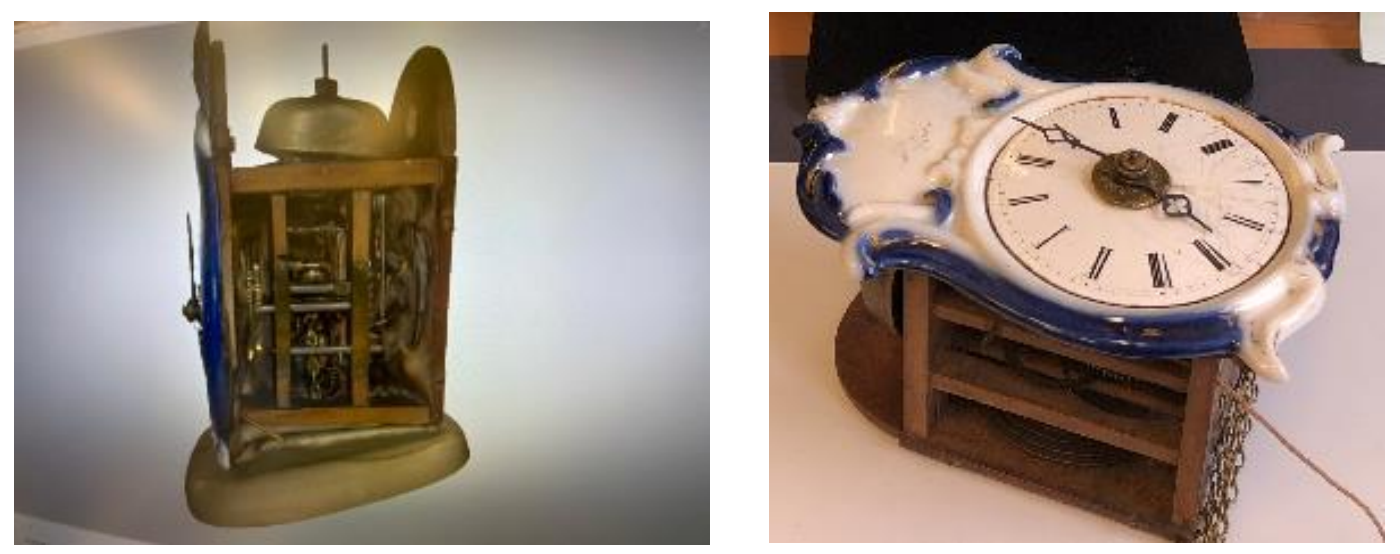

Figure 6: Left resulting 3D model. Neither Spider nor Leo argued with the clock in this regard. The resulting model will need to be manually remodeled and modified in one of the specific programs, such as Blender. On the right are the specific clocks, which we tried to digitize with a clockwork

The method of photogrammetry, which we have already written about several times in this article, would be possible in some cases. Photogrammetry (sometimes SFM or Structure 
From Motion) is very simply a process that allows you to calculate the location of points in three-dimensional space. It does this through the use of photographs of an object that are captured from multiple angles using a camera or camcorder. If we want to use this method, we take a picture of the object from all angles (the more photos are better and it is also advisable for the photos to overlap). We upload these images to a specialized program (such as Colmap, Zephyr, etc. [12]), which then looks for common elements in all the photographs. Then the program tries to calculate from what angle the subject was photographed in the given photograph. With this information about the angle and position of the camera, the software can then create a point in 3D space, which will corresponds to the element in the 2D photo. Ideally, we should get a flawless three-dimensional model. However, in most cases, we cannot achieve this without at least a basic repair of the model [12]. Even in this case, it is necessary to have powerful hardware. In addition, when taking photos, make sure that the surroundings of the subject are immutable.

Hence we do not rotate the object, but on the contrary we bypass the object ourselves. In case we would like to obtain a really high-quality final model, it is advisable to provide software that allows you to work with certain reference points (in this case, often in the form of QR codes). We then place them around the photographed object. It is also advisable to ensure perfect lighting conditions to get the best possible result. Such conditions can only be found in a laboratory environment, often thanks to other purchased equipment (such as photo or film lights). In this case, however, unlike the 3D scanners we use, the method will not be portable [12]. However, if we perfect the lights and possibly the reference points, the method of photogrammetry can of course be used in the field.

A certain form of photogrammetry is also used by software for 3D digitization through smart technologies, which we have also written about here. For example, Qlone or Trnio. So far, we do not consider these programs to be of such high quality that they allow us to fully digitize historical monuments and then we also need to archive or present them. However, the accelerating development of modern technologies cannot be denied (Figure 7).
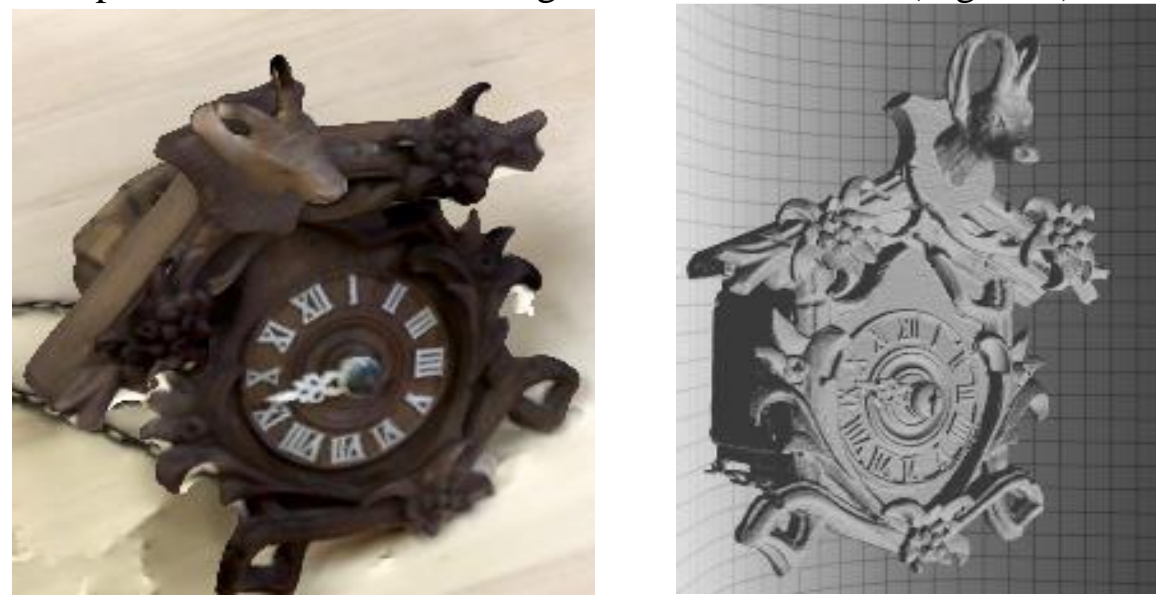

Figure 7: Left projection of a 3D digitized object in augmented reality.

The model was taken by the Trnio program installed on the iPad PRO 2020 device.

On the right, the same object but digitized by the Qlone program (also through the iPad PRO 2020 device). Unfortunately, this program digitizes without any texture

The model was taken by the Trnio program installed on the iPad PRO 2020 device. On the right, the same object but digitized by the Qlone program (also through the iPad PRO 2020 device). Unfortunately, this program digitizes without any texture. As can be seen in Figure 7 above, the technology is really advanced and it can be assumed that it is only a matter of time before we can use high-quality smart devices (such as tablets) with specific software for digitizing 3D objects. So far, however, the resulting models are not very suitable for other purposes of memory institutions such as museums, archives or galleries and the like. 
The last method we have not used for digitization yet, but it is one of the planned methods for our future projects, is the RTI method or Reflectance Transformation Imaging. This method, which should be able to display even poorly visible details in photographs, uses a sequence of still digital photographs of the subject from a constant camera position. Each individual photo is illuminated from a different angle. A mathematical model of the surface of the object being scanned is then synthesized from this image sequence [13, 15]. This method of digitization it can be used wherever classical 3D digitization fails. It can be ideal for very small objects such as coins, or for shiny and small objects (coins, jewelry), or for very fragmented objects, where it is necessary to monitor and capture each individual part (seals). In order to be able to use this method, it is necessary to have a really high-quality SLR camera as well as a series of lights or a straight specific dome-shaped construction, which ensures perfect illumination from all sides and the possibility of taking top quality pictures.

\section{CONCLUSION}

In many countries, a large number of projects, programs and activities related to the digitization of cultural heritage are currently being addressed, both at the local level and in the framework of international cooperation. The current trend is 3D digitization and documentation of cultural heritage objects. This is undeniably a very demanding process, which can be facilitated by suitable modern technology. The so-called 3D scanners digitize in different quality, they can capture objects of different sizes. The added software then allows you to process data in an intuitive or very complicated way. The individual methods of digitization thus differ significantly.

From our point of view, it works best for us so far in our digital laboratory to combine work with Artec Space Spider and Artec Leo scanners. Of course, these solutions will not work in every situation (nor, most often due to the high purchase price in every institution). It is possible to consider another mentioned method of digitization, namely photogrammetry, which will be very useful in many cases.

This digitization project is still ongoing, in part because other historical pieces of the clock are still being digitized. Another reason is because we are in the phase of finding the most suitable technology for long-term display of 3D data through a web browser. Web services and portals that are designed to share and often trade 3D models online are a relatively standard and affordable service, but this is especially true for commercial solutions. Creating a freely accessible, for example, a museum collection of digitized objects is a matter that has not been around for a long time. Even so-called virtual museums are still not a common part of the offer of all museums, despite the current pandemic situation, when it is almost unthinkable to go to see the museum collection in person. Thus, a further step after the completion of the digitization of the entire collection will be to place this data on the web and make it available to the general public, preferably through a service that will not be too complicated and will allow for viewing of collection items not only from a computer but also from smart devices, such as smartphones or tablets. We therefore hope that in the future we will be able to expand this research and inform our colleagues about our next step in the field of digitization, protection and access to historical heritage.

\section{REFERENCES}

[1] M. Giakalaras. “3D Technologies for Cultural Heritage. Gaming Engines.” Department of Cultural Technology and Communication, University of Aegean, Lesvos 81100 Greece. 2020.

[2] K.A. Zimmermann: History of Computers: A Brief Timeline, Live Science Contribution, 2017. URL: https://www.livescience.com/20718-computer-history.html.

[3] B. Curless, From Range Scans to 3D Models, volume 4, ACM SIGGRAPH Computer Graphics. 33, 2000. doi: 10.1145/345370.345399.

[4] Industrial 3D Measuring Systems with High-Speed Technology, GOM: a ZEISS Company, Germany, 2021. URL: https://www.gom.com/en/products/high-precision-3d-metrology.

[5] What is Structured Light Imaging? RT: Robotics Tomorrow, Robotics Tomorrow, USA, 2018. URL: https://www.roboticstomorrow.com/article/2018/04/what-is-structured-light-imaging/11821. 
[6] I. Grandič. 3D skener SLS-2 David, Česká republika: Ivo Grandič, 2020. URL: https://www.grandic.cz/skenery-david-3d-skener-sls-2-david.

[7] Sprout Pro by HP G2 - Pořizování 3D snímků s nástrojem Work Tools Camera 3D, HP Development Company, L.P., Českárepublika, 2021. URL: https://support.hp.com/cz-cs/document/c06213399.

[8] Artec 3D Scanners, USA: Artec 3D Europe, 2021. URL: https://www.artec3d.com.

[9] E. M. Di Paolo. Vertical-Cavity Surface-Emitting Lasers for 3D Depth Detection, EDN: Asia, Cambridge, MA, USA: Aspencore, 2019. URL: https://www.ednasia.com/vertical-cavity-surface-emitting-lasers-for-3ddepth-detection/.

[10] K. Rybenská, 3D digitalizace vybrané sbírky hodin, 21. Konference: Archivy, knihovny, muzea v digitálnímsvětě, Praha, 2020.

[11] G. Pavlidis, A. Koutsoudis, F. Arnaoutoglou, V. Tsioukas, Ch. Chamzas. Methods for 3D digitization of Cultural Heritage, in: Journal of Coultural Heritage (Ed.), Vol. 8, 1, 2007: pp. 93-98. doi: 10.1016/j.culher.2006.10.007.

[12] M. Zuza. Fotogrammetrie - 3D skenování s použitímfotoaparátučimobilu, Josef Průša, Českárepublika, 2018. URL: https://josefprusa.cz/fotogrammetrie-3d-skenovani-s-pouzitim-fotoaparatu-ci-mobilu/.

[13] J. Plzák. Documentation of coins via Reflectance Transformation Imaging (RTI). in: Numismatické listy, Praha: Národní muzeum ve spolupráci s Českou numismatickou společností, 2016, pp. 169-174. doi: 10.1515/nl-2016-0010.

[14] N. Barbuti, G. De Felice, A. Di Zanni, P. Russo, and A. Valentini, Creating Digital Culture by co-creation of Digital Cultural Heritage: the Crowddreaming living lab method, Um. Dig., vol. 9, pp. 19-34, Dec. 2020.

[15] M. Brejcha, V. Brůna, Z. Marek, B. Větrovská, Metodika digitalizace, 3D dokumentace a 3D vizualizace jednotlivých typů památek: certifikovaná metodika. Ústí nad Labem:Národní památkový ústav, územní odborné pracoviště v Ústí nad Labem, 2015. Odborné a metodické publikace (Národní památkový ústav). ISBN 978-80-85036-61-9. 